\title{
The Influence of Customer Participation in Value Co-creation Activities on Consumer WOM Communication
}

\author{
Yue Liu ${ }^{1 a^{*}}$ \\ ${ }^{1}$ School of Management, Wuhan University of Technology, Wuhan, P.R.China \\ a1455384211@qq.com
}

Keywords: Customer participation; Value co-creation; Customer perceived usefulness;WOM Communication; Consumer behavior; Customer professionalism

\begin{abstract}
The development of network economy and vary $\mathrm{O} 2 \mathrm{O}$ channels provides more ways to participate in the enterprise value co-creation for the customer, exploring the customer participation activities is important to study the consumer behavior. Through questionnaire analysis, this paper empirically studies the relationship among customer participation, customer perceived usefulness and consumer word-of-mouth communication behavior, and verifies the moderating effect of customer professionalism on customer perception. The empirical research shows that: enthusiasm, conscious participation and social activities will further affect the word-of-mouth behavior of consumers and professional higher customers show more easily customer perception than the lower. The research conclusion has an important theoretical and practical significance for modern enterprises to analyze consumer behavior and the future trend of activities.
\end{abstract}

\section{Introduction}

According to the Chinese Internet Network Information Center (CNNIC) released in the fortieth "China Internet development statistics report" Chinese users reached 751 million, Internet penetration rate reached $54.3 \%$, the dominant position of the mobile Internet is increasingly strengthened, more and more people to establish links between themselves and the brand through the mobile internet ${ }^{[1]}$. Now companies are beginning to realize by means of social network media improve the participation of customers, enhance customer perceived value, so as to achieve the purpose of influencing consumer behavior. In the early studies of WOM, most of them use the WOM as a consumer satisfaction and consumer perception of the antecedent variables, this study will explore it as antecedents of customer participation.

The customer as a kind of invisible assets are more and more people pay attention to the use of appropriate, customers can not only bring great competitive advantage for the enterprise, will bring benefits to customers, and let them get higher satisfaction (Chen ,2006) ${ }^{[2]}$. The ability of customers to participate in brand building is strengthened, and enterprises need to find the trend of consumer behavior in order to remain invincible in the competition. This study is mainly from the perspective of customer participation, through the empirical research on the effect of customer participation mechanism on consumers' word-of-mouth behavior, and explore the mediating role of customer perceived usefulness and the intermediary role of customer professional degree.

\section{Theoretical Background and Research Hypothesis}

Customer Participation In Value Co-creation And Customer Perceived Usefulness. A large number of studies at home and abroad have shown that customer participation in value creation will affect customer value perception. In the process of participating in value co-creation, the trust between users in social networking sites can promote the trust between other users, thus creating the perspective value of consumers ( $\mathrm{Li}$ et al., 2014) ${ }^{[3]}$. The brand increases the marketing effect of the brand and enhances the perceived usefulness of consumers through the way of value creating activities and increasing the social interaction with the customers. Yuan Ting et al. (2015) based on customer experience, discussed the influence of value co creation activities on customer value ${ }^{[4]}$. By participating in value creating activities, customers create service products and the experience 
environment together, which has an impact on customer perception. C.F Chen (2016) points out that customers participate in value co-creation and perceive value to achieve customer loyalty ${ }^{[5]}$. In the current era of experience economy, appropriate and effective customer participation can enhance customer perceived value of product, reduce the risk perception of product quality customer products, reduce the cost of acquisition, can bring customer experience value, relationship value, learning value and psychological benefits value (W.B Liu and R.Q Chen, 2009) ${ }^{[6]}$. In the process of customer participation in the customer to communicate through social interaction and enterprise, in this process, enterprises to understand customer demand for products of real, so as to improve their products and customized products to meet customer demand, increase the consumer perception of product will be useful in this process. Customer participation in value creating activities will increase the understanding of products, thereby affecting customer perceived usefulness of products.

Vivek (2009) divided the types of customer participation into conscious participation, enthusiastic participation and social interaction participation ${ }^{[7]}$. This study referred to Vivek (2009) on the dimensions of customer participation, and proposed the following hypotheses:

$\mathrm{H} 1$ : customer participation in value creating activities affects customer perceived usefulness. Conscious participation, enthusiastic participation and social interaction participation in value creating activities play a positive role in customer perceived usefulness.

Customer Perceived Usefulness And Consumer Word Of Mouth Behavior. A lot of research about the reputation that negative word-of-mouth will reduce the perceived usefulness of customers, positive word-of-mouth will enhance customer perceived usefulness, word-of-mouth will have a direct impact on customer perception. Gefen (2015) focuses on the perceived usefulness has been studied, and that the consumer is refers to the consumer that has the reputation network information value for the perceived usefulness of online word-of-mouth information, namely whether it can enrich the consumer product related information, and the final decision on consumer behavior has significant effect ${ }^{[8]}$. Consumers to participate in the activities in the process of value creation, access to more information of consumer word-of-mouth, the possibility to obtain the useful information related to the product is also bigger, thereby enhancing the perceived usefulness of consumers, making it easier to generate word-of-mouth re diffusion intention . Ji Wu and other research (2017) show that customer participation increases the likelihood of word-of-mouth communication, but it is not verified by the perceived usefulness of customers as a medium ${ }^{[9]}$. Wu Shuil ong et al. (2017) found that consumers with positive experience had higher intention to spread word of mouth than consumers who suffered from negative experience. Consumers who experience positive experiences are more likely to perceive the usefulness of the product than the negative experience or the lack of consumers ${ }^{[10]}$. Based on this, the hypothesis is put forward.

$\mathrm{H} 2$ : customer perceived usefulness is positively correlated with consumer word-of-mouth communication behavior. The stronger the perceived usefulness of the product, the more likely it is to produce word of mouth communication; the weaker the perceived usefulness of the product, the less likely it is to produce word of mouth transmission.

The Moderating Role of Customer Specialization. Customer specialization refers to the accumulation of knowledge about pr oduct information, product use and product performance, which indicates the ability of individuals to solve problems related to the product. Study on the professional degree of customers has been a hot issue on the field of consumer behavior, such as the impact of customer professional degree of information search and information processing, product involvement, product evaluation, price perception accuracy and product diffusion etc.. Customer professionalism is strong, indicating strong information processing ability, product involvement is high.

A large number of studies have shown that customer perception is affected by its own characteristics. Researchers pointed out that the influence of customer qualification on community participation was different through the study of online brand community, and the influence of community participation was more significant for long-term qualification customers than short-term qualification clients. Some scholars study the role of customer professionalism in customer 
perception from the perspective of consumer self construal. The customer will bring professional and strong self-confidence, believe that their own perception in brand choice or product experience, Anders Hauge Wien (2017) to explore the impact of social consumer confidence and consumer confidence on word-of-mouth, research demonstrates that consumer confidence will have an impact on customer perceived to influence consumers' word-of-mouth behavior. Mitchell and other scholars found that professional comments can have an important impact on consumer behavior, consumer perception of the speech is more professional, the speech polarity influence perceived risk is more significant, more useful for their purchase decision and choice; consumers' perception of the speech will eventually impact on purchase intention. To create the value of customer participation in activities, professional and strong in product or high complexity in the industry, customers often hope that through professional knowledge training to enhance professional customers so as to enhance the perceived usefulness of consumer products. Huang Minxue et al. (2014) based on the empirical study of the paradox of fund investors' customer specialization, pointed out that higher professional customers had higher perceived ease of use, perceived service quality, and expected service $^{[11]}$. Customer participation is helpful to improve the service to create value, increase customer satisfaction and enterprise and its employees, depending on the customer in different situations, whether they are of high quality, with the enterprise standard to participate in the service process, but also depends on whether the enterprise and customer service cooperation and jointly create a suitable atmosphere to create . there have exsisted study emphasizes the enterprise and customer support each other on an important role in realizing the value creation, and puts forward the skills and knowledge can affect customer value creating. With the improvement of customer capabilities, customers will actively put their knowledge and skills into the value creation. In the process of customer participation in value creation, perceived product information and customer word-of-mouth exposure, customers should use their own professional to judge it. Based on this, the hypothesis is put forward:

$\mathrm{H} 3$ :Customer specialization plays a moderating role in the process of customer participation in value creating activities and customer perceived usefulness.

Figure 1 shows the construction of conceptual model

Customer participation in value creating activities

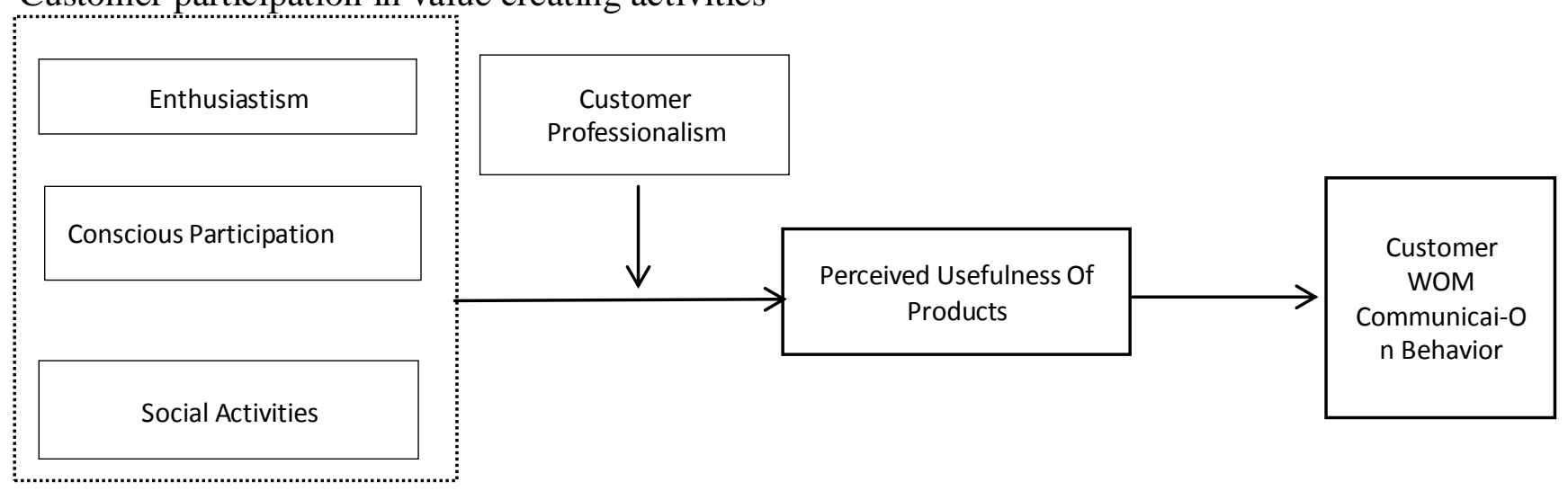

Figure 1.Construction of conceptual model

\section{Questionnaire Design}

In this study, a questionnaire survey was used to collect data. In order to ensure the effectiveness of the questionnaire, we drew on the mature scale of foreign scholars and adjusted the actual needs of the research. Because the research topics relating to the relationship between customer participation, customer satisfaction, customer perceived professional and consumer word-of-mouth behavior, so the measurement variable is the value of customer participation in customer activities, create a professional and consumer perceived usefulness, consumer word-of-mouth for four.

People who have participated in the activities of consumers brand mobile phone as the research object, let them recall once participated in the activities of the most profound memory of the brand 
mobile phone, in the basic information survey, including age, gender, education of consumers and the purchase of 3 options, a total of 18 items. We used Likert 5 scale, make the survey to fill out the questionnaire according to the actual situation, select the 1-5 score, 1 said "strongly disagree", 5 said "strongly agree", the degree of 1-5 increases, respectively "strongly disagree", "no" and "not sure" "the same meaning" "very much agreed".

\section{Empirical analysis}

In this study, SPSS24.0 was used to analyze and draw conclusions. In this study, a total of 280 questionnaires were sent out, and 225 were recovered, with a recovery rate of $80.35 \%$. Table 1 shows the demographic characteristic. Table 2 shows the Cronbach's alpha of all the variabilities.we can see that the overall scale of the Cronbach's alpha coefficient is $0.769>0.7$, so the study of each part of the scale to meet the basic requirements of reliability, can analyze the next step.

Table 1 Demographic characteristic $(n=207)$

\begin{tabular}{clll}
\hline Demographic profile & & Frequency & Percent \\
\hline gender & Male & 97 & 46.9 \\
& Female & 110 & 53.1 \\
& & & \\
\hline age & Less than 18 & 4 & 1.9 \\
& $18-30$ & 149 & 72.0 \\
& $30-40$ & 46 & 22.2 \\
& $>=40$ & 8 & 3.9 \\
& & & \\
\hline Education & Bachelor & 180 & 87.0 \\
& Master & 16 & 7.7 \\
& Doctor & 6 & 2.9 \\
& High school or & 5 & 2.4 \\
& below & & \\
& & & \\
& & 34 & 16.4 \\
& Student & 20.8 \\
& Enterprise & 43 & 37.7 \\
& Government & 21 & 15.0 \\
& office & 78 & \\
& Public services & 31 & \\
& Other & & \\
& &
\end{tabular}

Table 2.Cronbach alpha

\begin{tabular}{cc}
\hline Research variables & Cronbach's alpha \\
\hline Customer participation & 0.863 \\
\hline Customer Professionalism & 0.742 \\
\hline PerceivedUsefulness Of Products & 0.738 \\
\hline $\begin{array}{c}\text { Customer WOM Communicai-On } \\
\text { Behavior }\end{array}$ & 0.821 \\
\hline Total & 0.769 \\
\hline
\end{tabular}

In Table 3, we can see the T-value of variables in hypothesis 1 and hypothesis 2 are $<0.001$, so the data confirm our conclusion. 
Table 3 .result of analysis

\begin{tabular}{llll}
\hline Hypothesis & Standarized coefficient & T-value & Conclusion \\
\hline 1 & $0.197 * * *$ & supported \\
\hline 2 & $0.478^{* * *}$ & supported \\
\hline
\end{tabular}

Note: Significant at: $* \mathrm{p}<0.05, * * \mathrm{p}<0.01, * * * \mathrm{p}<0.001$.

Added the customer professional variables, we can see that the correlation coefficient of CPA-UP are increased. So the control respose of CP are existed.

Table 4. control response of customer professionalism

\begin{tabular}{lll}
\hline & CPA & UP \\
\hline CPA & & $0.215^{*}$ \\
\hline $\mathrm{UP}$ & $0.141^{*}$ & \\
\hline $\mathrm{CP}$ & & $0297^{* *}$ \\
\hline $\mathrm{UP}$ & $0.262^{* *}$ & \\
\hline
\end{tabular}

Note:CPV:customer participation activities,UP:usefulness perception,CP:customer professionalism

\section{Summary}

The results of empirical research show that customer participation in value co-creation activities affects consumers' perception of product usefulness, and is influenced by customer professional strength in the process. Therefore, in the process of consumer investigation, enterprises should pay attention to the professional background of consumers, and provide consumers with the services they need most. The perception of customer product usefulness will directly affect their word-of-mouth communication behavior, and then have an important impact on corporate brand. Enterprises should pay attention to the relationship among them, in order to facilitate the sustained and long-term development of enterprise products.

This study explores the relationship between customer participation in value co-creation activities, consumer product useful perception and consumer word-of-mouth communication behavior, which has guiding significance for the development of enterprises in three aspects. However, choosing mobile phone brand participation activities as the main activity scene of questionnaire design has limitations, and the future research should make a survey on different industries, and make a comprehensive comparison.

\section{References}

[1] China Internet Information Center CNNIC, statistical report on the development of China's Internet[R], 2016, Beijing

[2] Customer participation, value co-creation and customer loyalty a case of airline online check-in system, W.B Liu, Computers in Human Behavior 62 (2009), 346-352.

[3] The influence of Internet word of mouth and value co creation on consumer purchase intention: Li Jia, Xu Da, Chen Xia, Lv Tingjie, 2014, Journal of Beijing University of Posts and Telecommunications (SOCIAL SCIENCES EDITION).(In Chinese)

[4] A influence on customer value research based on the mediating effect of customer experience; T.Yuan , S.Q.Er, 2015, research on financial and economic issues.(In Chinese)

[5] Customer participation, value co-creation and customer loyalty a case of airline online check-in system, C.F Chen, J.P Wang, Computers in Human Behavior ,(2016) 346-352.(In Chinese)

[6] Resident-tourist value co-creation: The role of residents' perceived tourism impacts and life satisfaction, Z.b. Lin, Ye Chen ，Raffaele Filieri, Tourism Management 61 (2017) 436e442

[7] Vivek, S.D. (2009). A scale of consumer engagement (Doctoral dissertation, The University of 
Alabama TUSCALOOSA).

[8] The role of electronic Word-of-Mouth and trust - A theoretical analysis, Gefen, Computers in Human Behavior 31 (2015) 182 - 189.

[9] Community engagement and online word of mouth: An empirical Investigation, Ji Wu a, Shaokun Fan b , J. Leon Zhao c, 2017, information and management.

[10] W.S Long, B.Ying, Y.Y Na and J.Li:Influence Boundary And Mechanism Of Electronic WOM.Journal of management engineering,(2017)No.02,p.55-63.(In Chinese)

[11] M.X Huang,F.Wang,Maxine Hong Kingston. A survey of word-of-mouth communication and its research in network environment [J]. Journal of management, 2010,01:138-146.(In Chinese)

[12] Cossí o-Silva F. J, R evilla-Camacho M. , Vega-Vázquez. Value Co-creation and Customer Loyalty [J]. Journal of Business Research, 2015, 69( 5) : 1621-1625. 